\title{
Retractation note: Road Traffic Monitoring System with Self- Learning Function using the Raspberry Pi Platform
}

Jacek Zaucha ${ }^{1}$, and Maciej Matczak ${ }^{1}$

Cosmin Rus ${ }^{1, *}$, Răzvan Marcuș ${ }^{1}$, and Olimpiu Stoicuța ${ }^{1}$

${ }^{1}$ University of Petrosani, Department of Automation, Computers,Electrical Engineering and Energetics,University Street 20, Petroșani,332006, Romania

Original article: MATEC Web of Conferences 290, 06009 (2019), https://doi.org/10.1051/matecconf/201929006009

The authors, Cosmin Rus, Răzvan Marcuş and Olimpiu Stoicuța, regret that this article is an accidental duplication of an article that has already been published: https://www.mathworks.com/matlabcentral/fileexchange/52456-analyzing-trafficusing-a-webcam-a-raspberry-pi-and-thingspeak. The duplicate article has therefore been withdrawn. The Guest Editors have given their approval for this decision. 